\title{
OP75
}

\section{USE OF AN IMAGING LUMINANCE MEASURING DEVICE TO EVALUATE ROAD LIGHTING PERFORMANCE AT DIFFERENT ANGLES OF OBSERVATION}

\author{
FLORIAN GREFFIER et al.
}

DOI 10.25039/x46.2019.OP75

from

CIE x046:2019

Proceedings

of the

29th CIE SESSION

Washington D.C., USA, June 14 - 22, 2019

(DOI 10.25039/x46.2019)

The paper has been presented at the 29th CIE Session, Washington D.C., USA, June 14-22, 2019. It has not been peer-reviewed by CIE.

(C) CIE 2019

All rights reserved. Unless otherwise specified, no part of this publication may be reproduced or utilized in any form or by any means, electronic or mechanical, including photocopying and microfilm, without permission in writing from CIE Central Bureau at the address below. Any mention of organizations or products does not imply endorsement by the CIE.

This paper is made available open access for individual use. However, in all other cases all rights are reserved unless explicit permission is sought from and given by the $\mathrm{CIE}$.

CIE Central Bureau

Babenbergerstrasse 9

A-1010 Vienna

Austria

Tel.: +43 17143187

e-mail: ciecb@cie.co.at

www.cie.co.at 


\title{
USE OF AN IMAGING LUMINANCE MEASURING DEVICE TO EVALUATE ROAD LIGHTING PERFORMANCE AT DIFFERENT ANGLES OF OBSERVATION
}

\author{
Greffier, F. ${ }^{1}$, Muzet, V. ${ }^{2}$, Boucher, V. ${ }^{1}$, Fournela, F. ${ }^{1}$, Dronneau, R. ${ }^{1}$ \\ ${ }^{1}$ Cerema, Laboratory Department of Angers, FRANCE \\ ${ }^{2}$ Cerema, Laboratory of Strasbourg, FRANCE \\ florian.greffier@cerema.fr
}

DOI $10.25039 / \times 46.2019 .0 P 75$

\begin{abstract}
In this paper, we present a new approach to evaluate the performance of road and tunnel lighting based on luminance measurements. Combined with the abilities of an ILMD used in a moving vehicle, our proposal allows us to focus on other angles of observation of road more suitable for urban driving. Our first results show that changing angle of observation has an influence on average luminance of road surface and on associated uniformities.
\end{abstract}

Keywords: road lighting, dynamic luminance measurements, Imaging Luminance Measuring Device (ILMD), moving observer, angles of observation

\section{Introduction}

A large part of the information used by a driver is supplied to him by his visual system. Therefore, most specifications of road equipment standards are directly derived from human visual abilities. We can mention standards referring to road markings (CEN, 2018) or road signs, and especially to road and tunnel lighting installations.

Performance requirements of road and tunnel lighting are defined in CIE (International Commission on Illumination) or CEN (European Committee for Standardization) documents. For drivers of motorized vehicles, the main lighting criteria are based on the road surface luminance and include the average luminance, the overall uniformity and the longitudinal uniformity. Conventionally, in these documents, the driver's eye is assumed at $1.5 \mathrm{~m}$ above the road surface and the angle of observation is fixed to $1^{\circ}$ below the horizontal, corresponding to a distance of $86 \mathrm{~m}$ ahead of the observer. This geometry is well adapted for a speed of $90 \mathrm{~km} / \mathrm{h}$, on motorways for example. On the other hand, for night driving in urban areas or in urban tunnels where speeds are generally in the range of 30 to $50 \mathrm{~km} / \mathrm{h}$, it seems interesting to define new angles of observation dedicated to these contexts, as proposed in (Chain, 2008); (Stockmar, 2015) and in the Empir SURFACE project (EMPIR, 2017); (lacomussi, 2017). So what is the impact of these new angles on the road surface luminance and on associated uniformities?

We propose here some initial answers thanks to the processing abilities offered by use of an ILMD. In a first time, we will recall standardization elements useful to conduct luminance measurements in traditional cases. We will present the ILMD developed by the Cerema and his utilisation in the standard geometry. We will then propose a new approach to implement measurements always with the usual angle of observation of $1^{\circ}$. In a second time, this new approach will allow us to change angle of observation and evaluate the effects on average luminance, overall uniformity and longitudinal uniformity. Finally, we will comment these tendencies and propose future studies to confirm our first results.

\section{International standards referring to road lighting measurements}

Performance requirements of road lighting are well defined in CIE (CIE, 2010) or CEN (CEN, $2015 a \& 2015 b$ ) documents. These documents specify a set of photometric requirements aiming at the visual needs of road users. For drivers of motorized vehicles for use on traffic routes, the main lighting criteria are based on the road surface luminance of the carriageway. 
The metrology to verify that the actual installation fits the requirements essentially relies on static measurements with a spot luminance meter. In road lighting, the nominal position of the grid points at which measurements are taken is defined in (CEN, 2015c); (CIE, 2019). In the longitudinal direction, the measurement field shall enclose two luminaires in the same row. In the transversal direction, the measurement field is positioned between two lane markings and can include several driving lanes as shown in Figure 1. The spacing of the points in the longitudinal and transverse directions shall be determined as follows:

- $D=S / N$ in the longitudinal direction where $D$ is the spacing between points in the longitudinal direction in meters and $S$ is the spacing between luminaires in the same row in metres. $N$ is the number of points in the longitudinal direction with $\mathrm{N}=10$ for $\mathrm{S}<=30 \mathrm{~m}$ and $\mathrm{N}$ is the smallest integer giving $D<=3 \mathrm{~m}$ if $S>30 \mathrm{~m}$.

- $d=W / 3$ in the transverse direction where $d$ is the spacing between points in the transverse direction in metres and $\mathrm{W}$ is the width of the lane in metres.

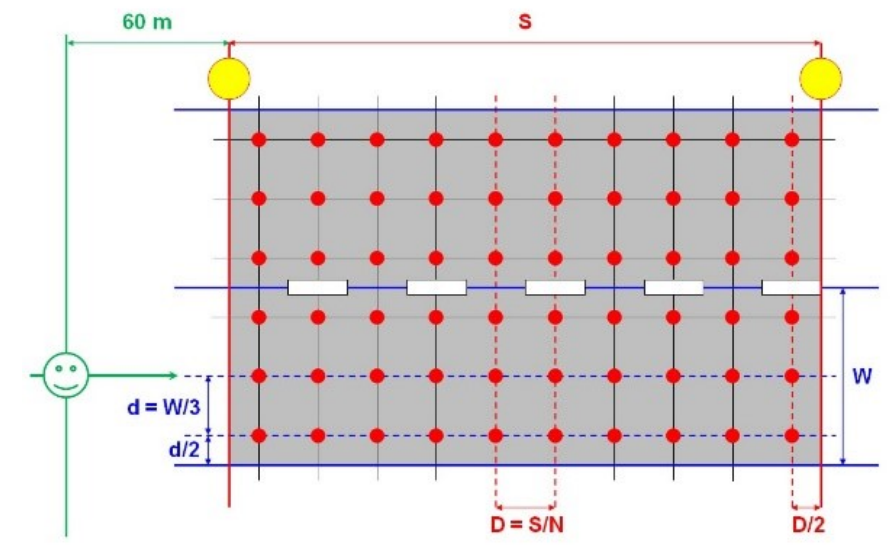

Figure 1 - Measurement grid points in road lighting

For static luminance measurement, the position of the luminance meter (symbolized with a smiley in Figure 1) is $1.5 \mathrm{~m}$ above the road surface and at $60 \mathrm{~m}$ ahead the field of the relevant area (CEN, 2015d). In the transverse direction, the luminance meter shall be positioned in the centre of each lane in turn.

From these luminance values, the following photometric parameters can be then calculated (CEN, 2015c); (CIE, 2019):

- The average luminance shall be calculated as the arithmetic mean of the luminance at the grid points in the field of measurement ;

- The overall uniformity shall calculated as the ratio of the lowest luminance, occurring at any grid point in the field of measurement, to the average luminance ;

- The longitudinal uniformity shall be calculated as the ratio of the lowest to the highest luminance on points in the longitudinal direction along centre line of lane.

Static measurements are mainly established for the reception of new installations, but cannot be applied for the diagnostic of a whole network. Dynamic measurements (CIE, 2002) have thus been developed and CIE has published a document on these devices (CIE, 2011). They are adapted to the diagnostic on carriageways over a large territory. The Cerema has developed since several years different ILMD (Greffier, 2015); (Boucher, 2017) that allow dynamic luminance measurements to be made.

\section{High Dynamic Range Imaging Luminance Measuring Device (HDR-ILMD)}

\subsection{Presentation of HDR-ILMD developed by Cerema}

An imaging system with a dynamic range comparable to the human eye able to measure luminance in motion has been developed by Cerema (Boucher, 2017). This High Dynamic 
Range (HDR) Imaging Luminance Measuring Device (ILMD) is based on four synchronous cameras (Figure 2). The photometric calibration leads to a reachable luminance range of six orders of magnitude (from $0.08 \mathrm{~cd} / \mathrm{m}^{2}$ to $163000 \mathrm{~cd} / \mathrm{m}^{2}$ ). The geometric calibration process is derived from stereoscopic systems. As such, rectified images facilitate the HDR construction 'hole filling' algorithm.
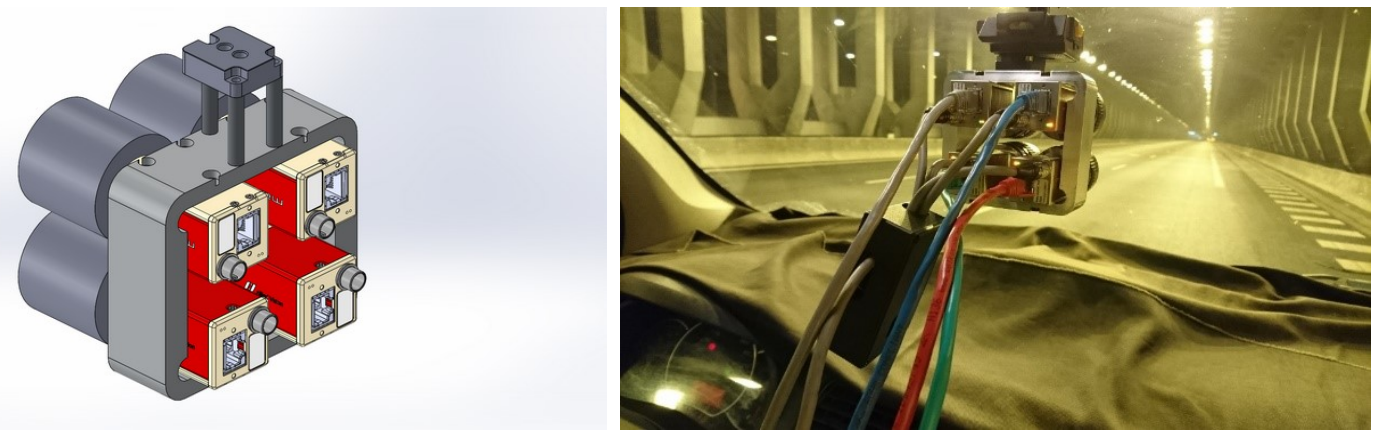

Figure 2 - HDR-ILMD developed by Cerema

\subsection{Application in road lighting}

For road or tunnel lighting measurements, the Cerema HDR-ILMD is fitted onboard a road operation vehicle (Figure 2). The normative measurement grid (Figure 1) is projected onto the images (Greffier, 2015). For grid points positioning in images, we compute a model that associates a distance to each line of the image. We apply the pinhole model for the camera and presuppose a locally flat road. In the longitudinal direction, the pinhole model allows determining the rows in the image that correspond to the limits of the measurement field (blue lines in Figure 3). In the transverse direction, the road markings equations, computed by using road marking detection and robust fitting, delimit each lane (red curves in Figure 3 ). Thus, we extract a Region Of Interest (ROI) from the image which matches the field of luminance measurement for the relevant area. The last step is to calculate in the ROI the best pixels corresponding to the grid points (green points in Figure 3 ). We obtain finally luminance values on the normative measurement grid (right picture in Figure 3).
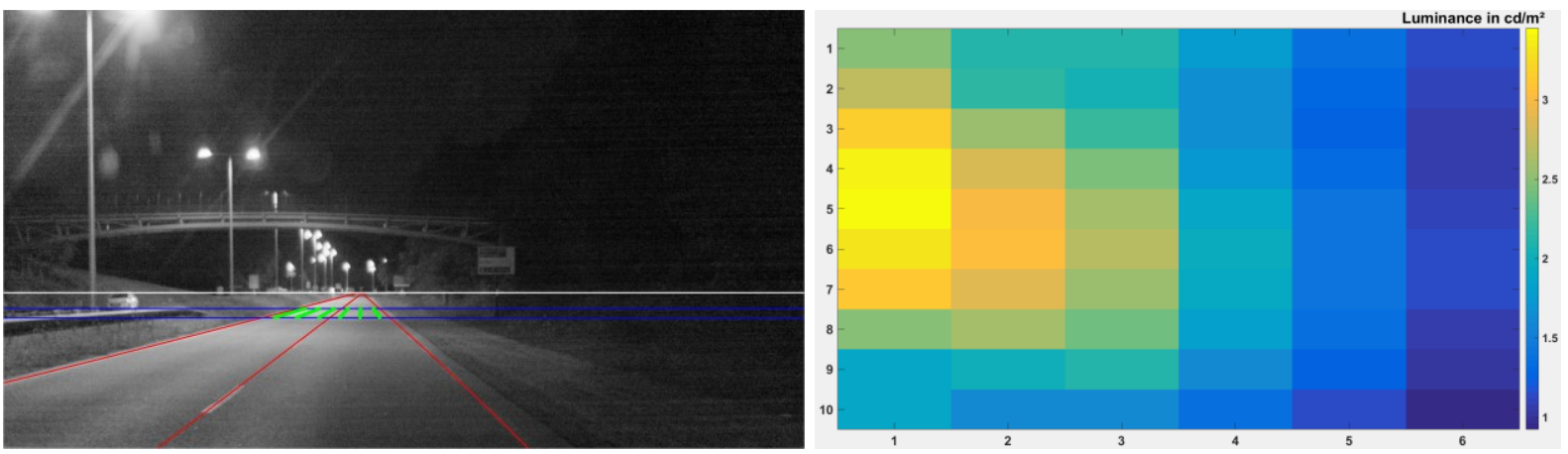

Figure 3 - Measurement grid points positioning (left) and luminances at the grid points (right) - (Greffier, 2015)

From these luminance values, classic average luminance, classic overall uniformity and classic longitudinal uniformity can be then calculated. Use of an HDR-ILMD also allows doing threshold increment measurements directly from luminance images (Boucher, 2017).

The vehicle is equipped with an odometer and a GPS to localize each image. In operating utilisation, the HDR-ILMD is set to make measurements every meter and thus is able to make a continuous assessment of a lighting installation as illustrated in Figures 4 and 5. To apply all methodological elements given in this paper, we used our ILMD measurements done in a real site during Lumiroute ${ }^{\circledR}$ study (Muzet, 2018). 


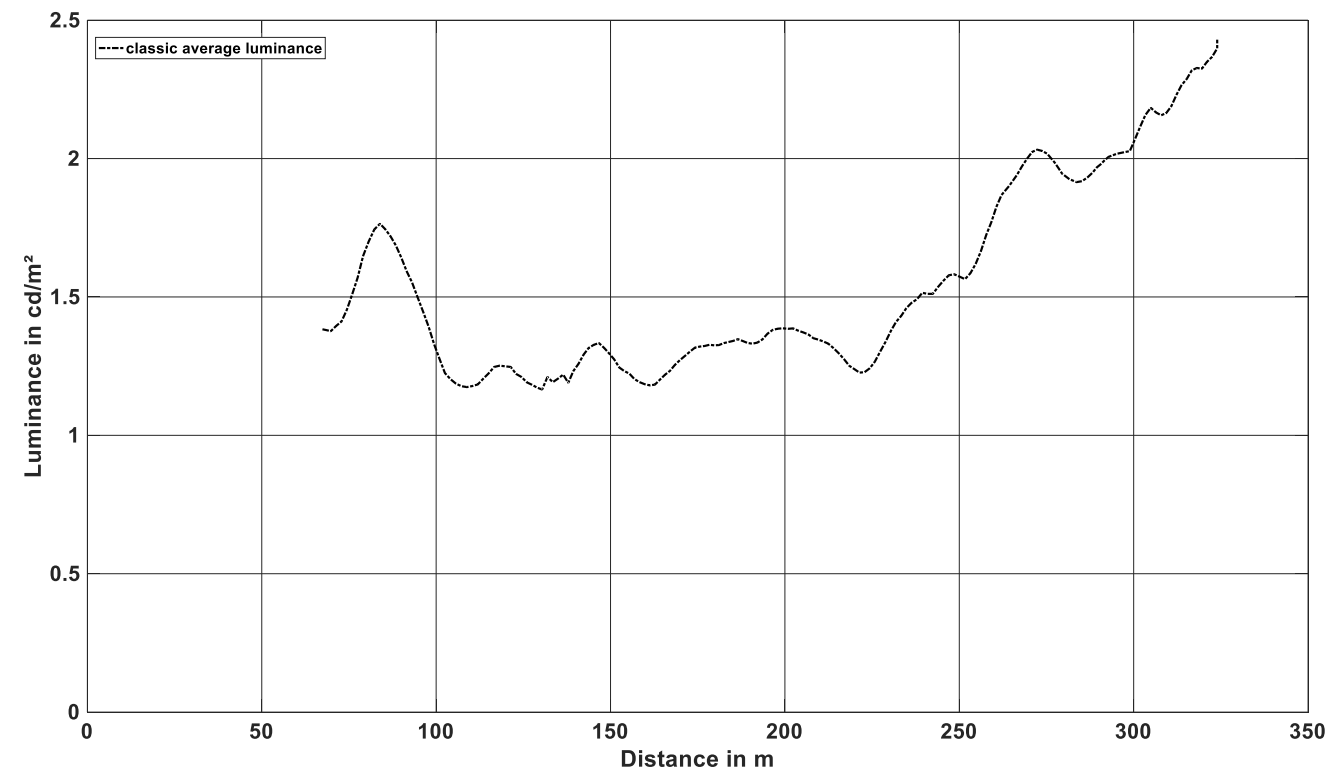

Figure 4 - Continuous average luminance measurements for classic methodology

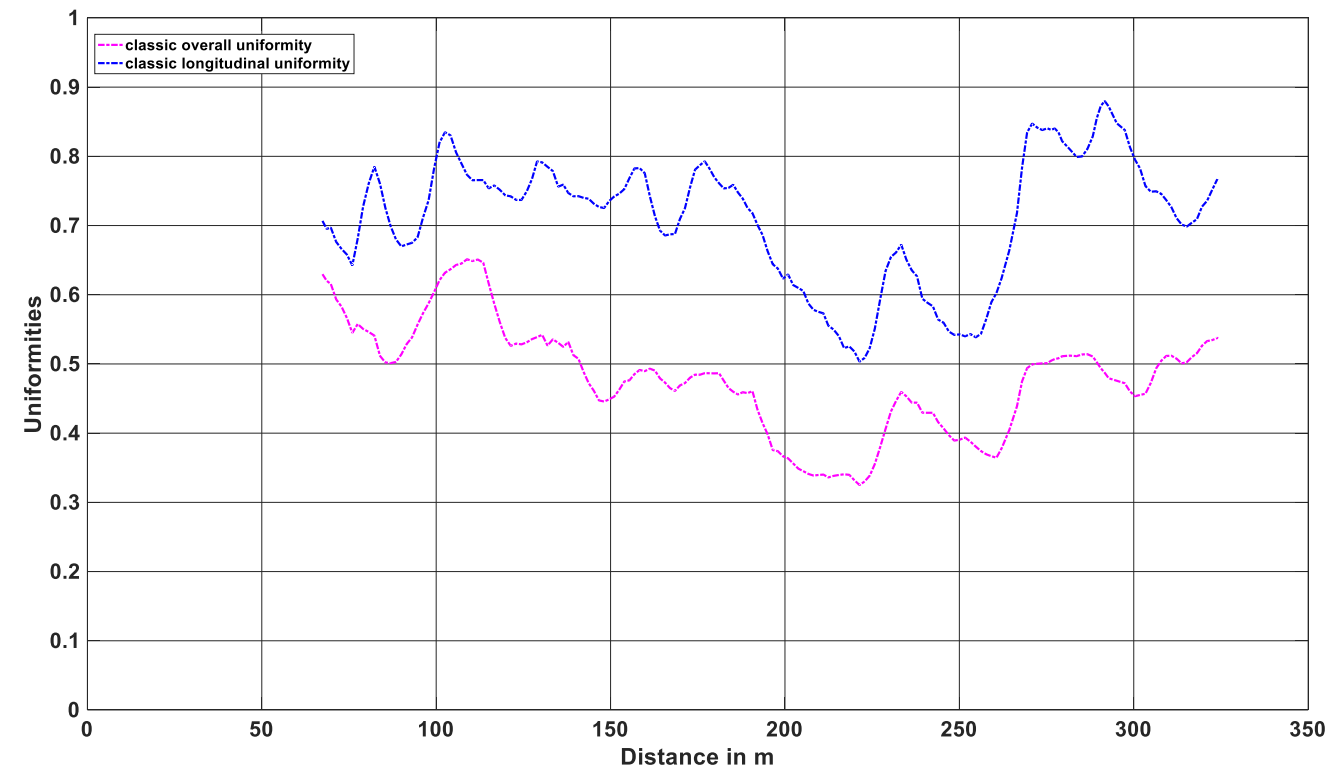

Figure 5 - Continuous uniformities measurements for classic methodology

\section{New approach for road lighting measurements at different angles of observation}

\subsection{Motivation}

In the previous sections, the explained methodology presents the use of an ILMD and dynamic measurements instead of the classic methodology done in static with a spot luminance meter. Thus, the ILMD is $1.5 \mathrm{~m}$ above the road surface and performs measurements in an area between $60 \mathrm{~m}$ and $90 \mathrm{~m}$ in front of the vehicle (for luminaires conventionally spaced $30 \mathrm{~m}$ apart). This classic configuration is representative of the classic " $1^{\circ}$ measurements", even if the observation angle varies in reality between $1.43^{\circ}$ (measurements at $60 \mathrm{~m}$ ) and $0.95^{\circ}$ (measurements at 90 $\mathrm{m})$. 
Since we want to assess accurately the influence of the angle of observation on the road surface luminance, this angle shall remain absolutely fixed for all the measurement grid. To be able to characterize the evolution of luminance between two luminaires and more generally along a street, as the angle and therefore the measuring distance are fixed, a solution could be to consider a moving observer as proposed by Stockmar (Stockmar, 2015). To test this solution, an ILMD in a moving vehicle can be used.

We first test the method for the $1^{\circ}$ angle and then applied it for other angles, that could be interesting for urban application. We tested several angles: the angle of $2.29^{\circ}$ because it is used in road marking, proposed by Sorensen (Sorensen, 2017) and in the Surface project (EMPIR, 2017); the angle of $3^{\circ}$ proposed by Stockmar (Stockmar, 2015); the angle of $5^{\circ}$ because it is the highest angle that we can test with our ILMD in this experimental configuration.

\subsection{Application of our method for $1^{\circ}$ fixed measurements}

In our new approach, the measurement area projected onto the images is fixed at a measuring distance that always offers the same angle of observation. The area still extends in the transversal direction over the entire width of the roadway by using road markings equations. In the longitudinal direction, it extends over a distance that allows a continuous measurement without overlap and without hole between two areas issues of two successive images. For example, since our ILMD records an image every meter, the fixed measuring distance will be $85.9 \mathrm{~m}$ and the area will therefore extend between $85.4 \mathrm{~m}$ and $86.4 \mathrm{~m}$. This configuration allows measurements to be made at an angle of $1^{\circ} \pm 0.01^{\circ}$.

To compare this approach with that using the conventional measurement grid, the portion of the roadway corresponding to the distance between two luminaires is reconstructed from successive images. In our example, the luminaires are spaced 30 meters apart. We therefore use 30 successive images that allows us to obtain a final measurement area of 30 meters long as for the classic grid. The reconstituted measurement area is then under-sampled to present finally 60 measurement points, 6 points in the transverse direction and 10 points in the longitudinal direction as for the classic grid.

Figures 6,7 and 8 show the evolution of the average luminance, overall uniformity and longitudinal uniformity over one of the sections of the Lumiroute ${ }^{\circledR}$ experiment. On these figures, we compare the classic measurements (already presented on Figure 4 and 5) with the measurements issued from our new approach with the $1^{\circ}$ fixed angle of observation.

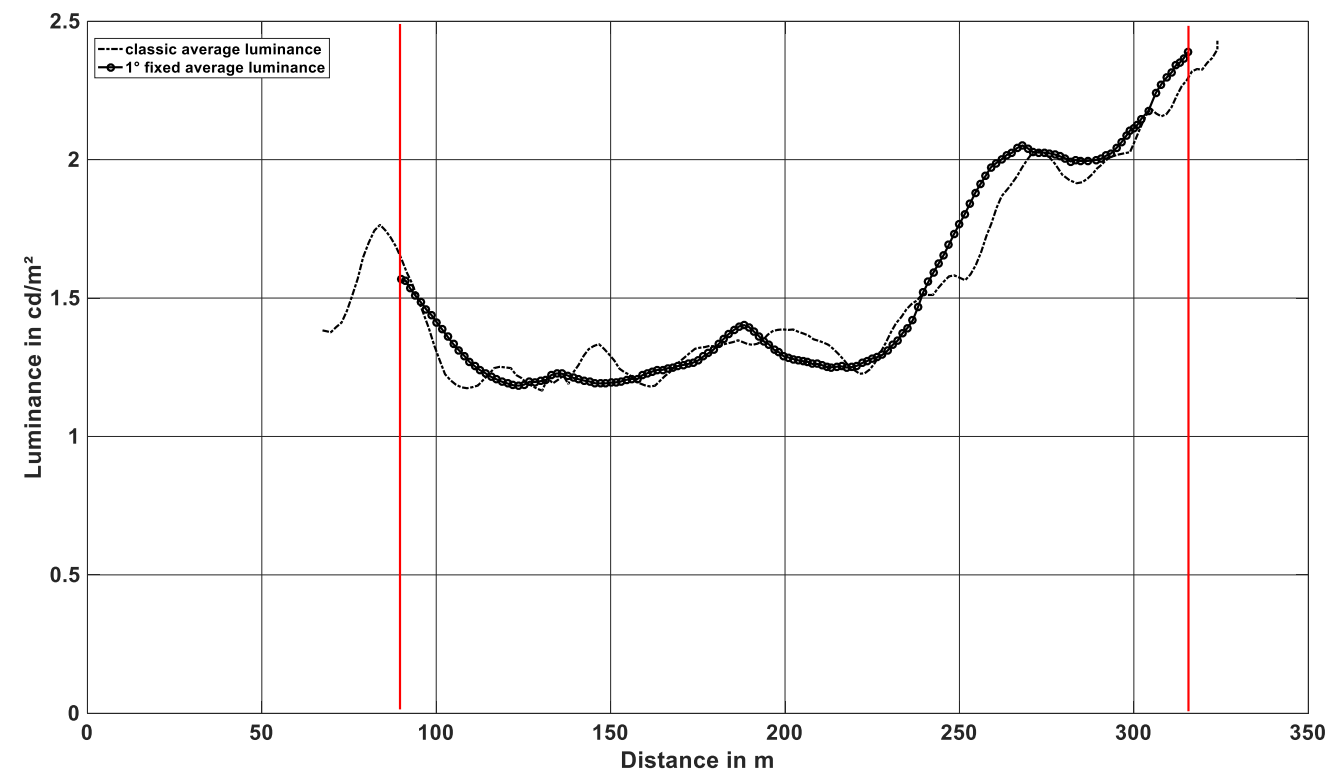

Figure 6 - Comparison of average luminance with classic measurements and with $1^{\circ}$ fixed measurements 


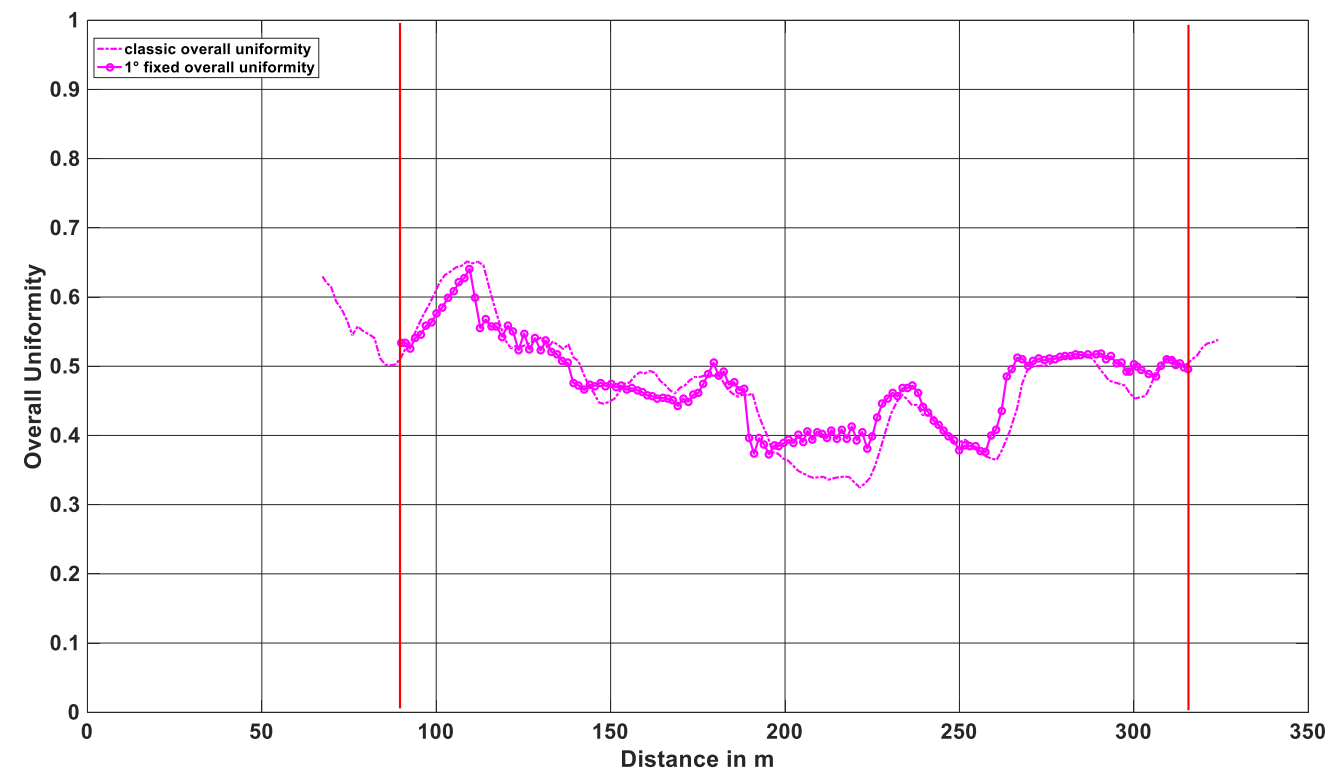

Figure 7 - Comparison of overall uniformity with classic measurements and with $1^{\circ}$ fixed measurements

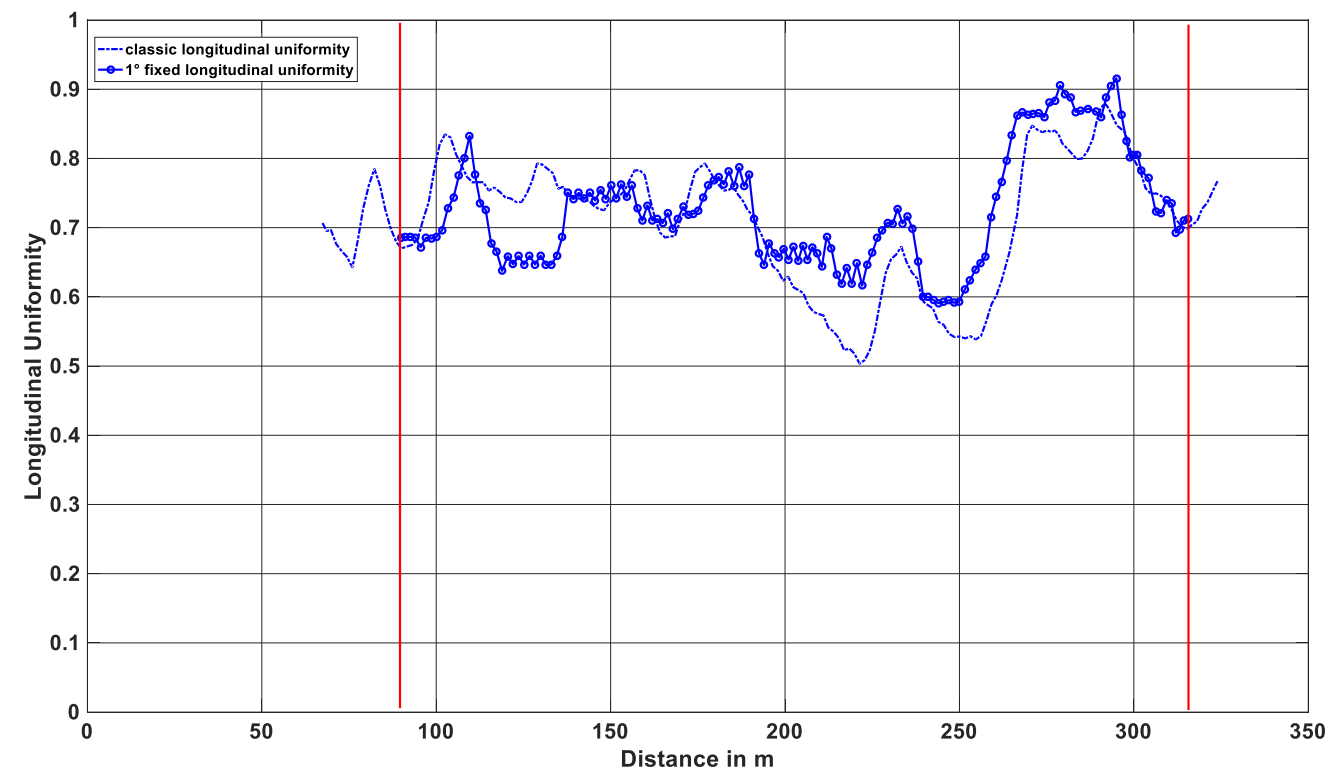

Figure 8 - Comparison of longitudinal uniformity with classic measurements and with $1^{\circ}$ fixed measurements

Table 1 summarizes the average luminance and uniformities values for the two image processing methods. Mean values were calculated between the vertical red lines, i.e. on the section common to both methods after correction of curvilinear abscissae. 
Table 1 - Average values comparison between classic measurements and $1^{\circ}$ fixed measurements

\begin{tabular}{|l|c|c|c|}
\hline & average luminance & overall uniformity & longitudinal uniformity \\
\hline Classic measurements & $1.50 \mathrm{~cd} / \mathrm{m}^{2}$ & 0.47 & 0.71 \\
\hline $1^{\circ}$ fixed measurements & $1.53 \mathrm{~cd} / \mathrm{m}^{2}$ & 0.48 & 0.72 \\
\hline Differences & $2 \%$ & $2 \%$ & $1 \%$ \\
\hline
\end{tabular}

Since the differences between the two methods are less than $2 \%$, we consider our approach to be a satisfactory alternative for applying it to different angles of observation.

\subsection{Application of our method for $2.29^{\circ}, 3^{\circ}$ and $5^{\circ}$ fixed measurements}

We applied our method for angles of $2.29^{\circ}, 3^{\circ}$ and $5^{\circ}$. The different measurement area for the different angles are represented on a road picture in Figure 9. The following table (Table 2) summarizes the geometric data associated with these new angle values.

Table 2 - geometric data associated with the different angle values investigated

\begin{tabular}{|c|c|c|c|}
\hline $\begin{array}{c}\text { fixed } \\
\text { angle }\end{array}$ & $\begin{array}{c}\text { measuring } \\
\text { distance }\end{array}$ & extent of measurement area & amplitude of fixed angle \\
\hline $1^{\circ}$ & $85.9 \mathrm{~m}$ & $85.4 \mathrm{~m}-86.4 \mathrm{~m}$ & $1.00^{\circ} \pm 0.01^{\circ}$ \\
\hline $2.29^{\circ}$ & $37.5 \mathrm{~m}$ & $37.0 \mathrm{~m}-38.0 \mathrm{~m}$ & $2.29^{\circ} \pm 0.03^{\circ}$ \\
\hline $3^{\circ}$ & $28.6 \mathrm{~m}$ & $28.1 \mathrm{~m}-29.1 \mathrm{~m}$ & $3.00^{\circ} \pm 0.05^{\circ}$ \\
\hline $5^{\circ}$ & $17.1 \mathrm{~m}$ & $16.6 \mathrm{~m}-17.6 \mathrm{~m}$ & $5.00^{\circ} \pm 0.15^{\circ}$ \\
\hline
\end{tabular}

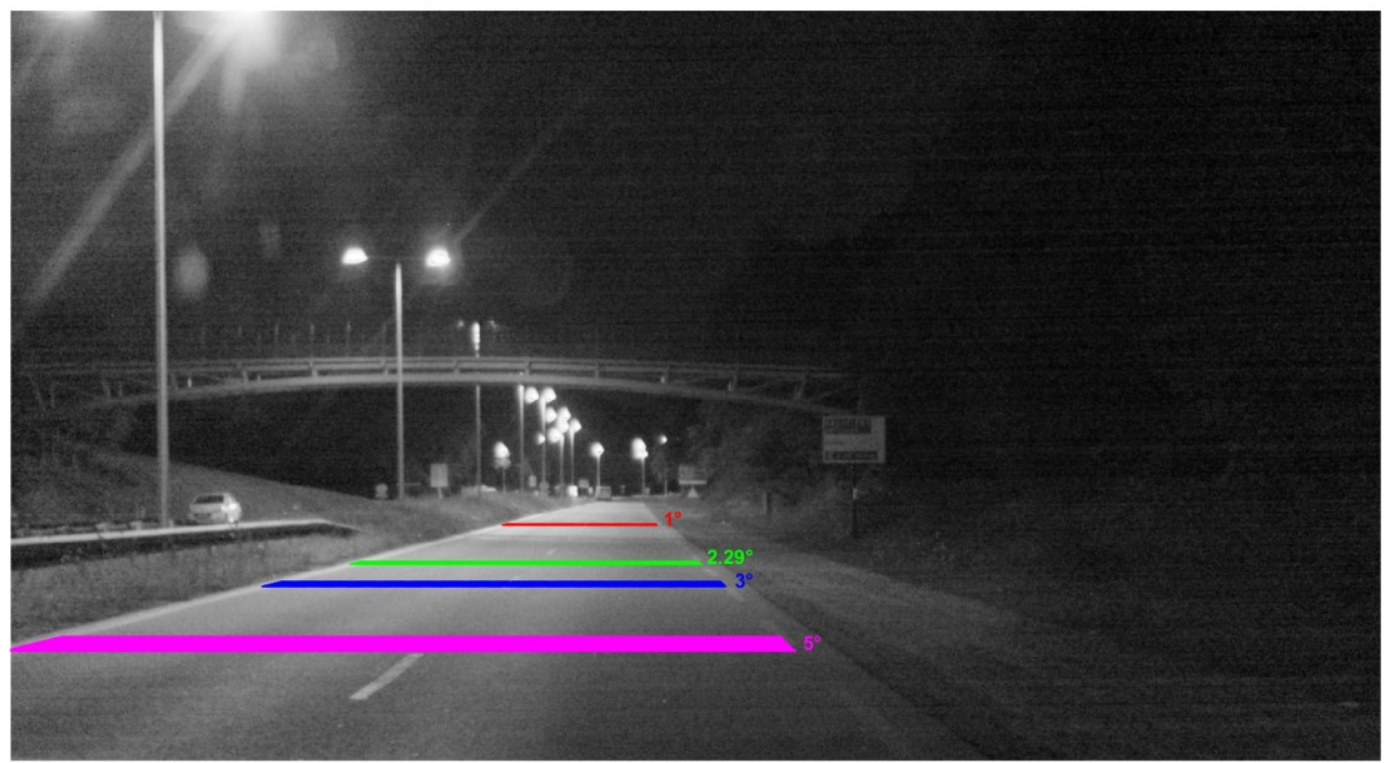

Figure 9 - Positioning of measurement area for $1^{\circ}$ (in red), $2.29^{\circ}$ (in green), $3^{\circ}$ (in blue) and $5^{\circ}$ (in pink)

Figures 10,11 and 12 show the evolution of the average luminance, overall uniformity and longitudinal uniformity for the four fixed angles of observation. 


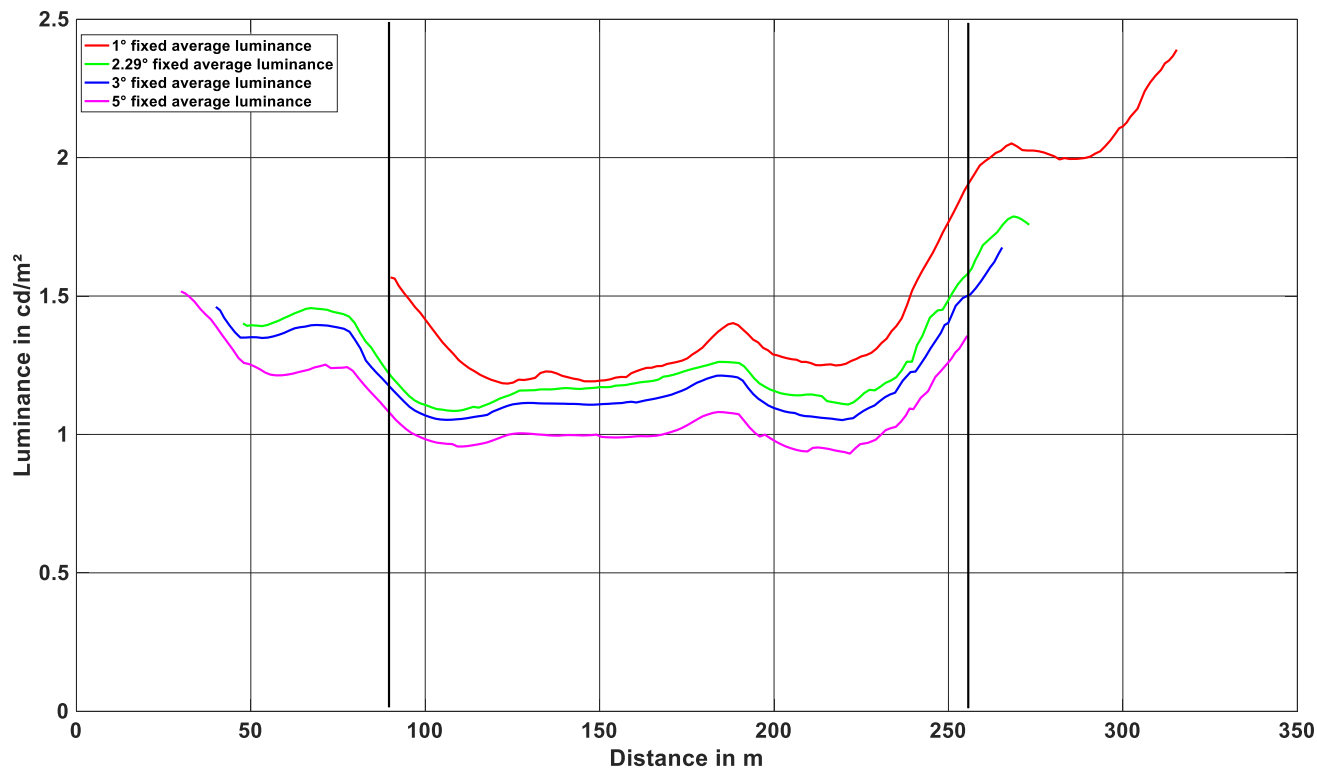

Figure 10 - Comparison of average luminance for $1^{\circ}$ (in red), $2.29^{\circ}$ (in green), $3^{\circ}$ (in blue) and $5^{\circ}$ (in pink) fixed measurements

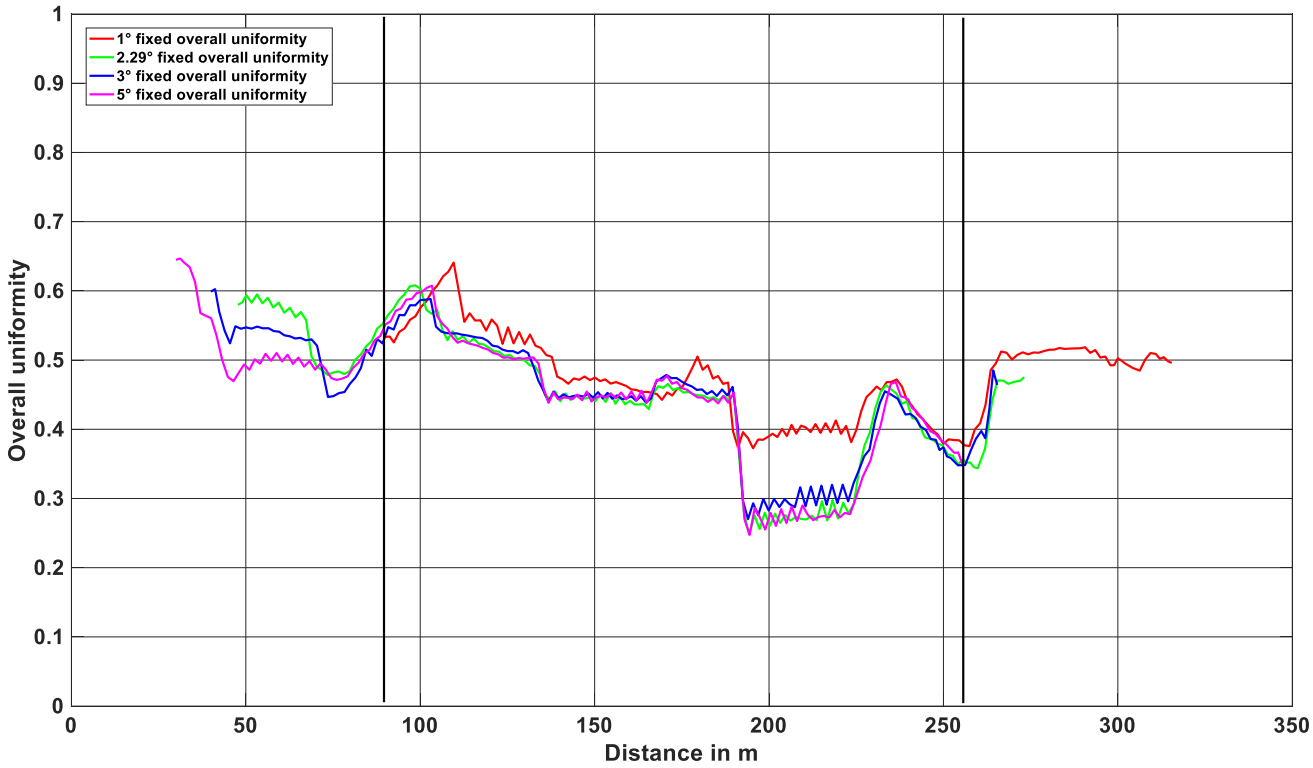

Figure 11 - Comparison of overall uniformity for $1^{\circ}$ (in red), $2.29^{\circ}$ (in green), $3^{\circ}$ (in blue) and $5^{\circ}$ (in pink) fixed measurements 


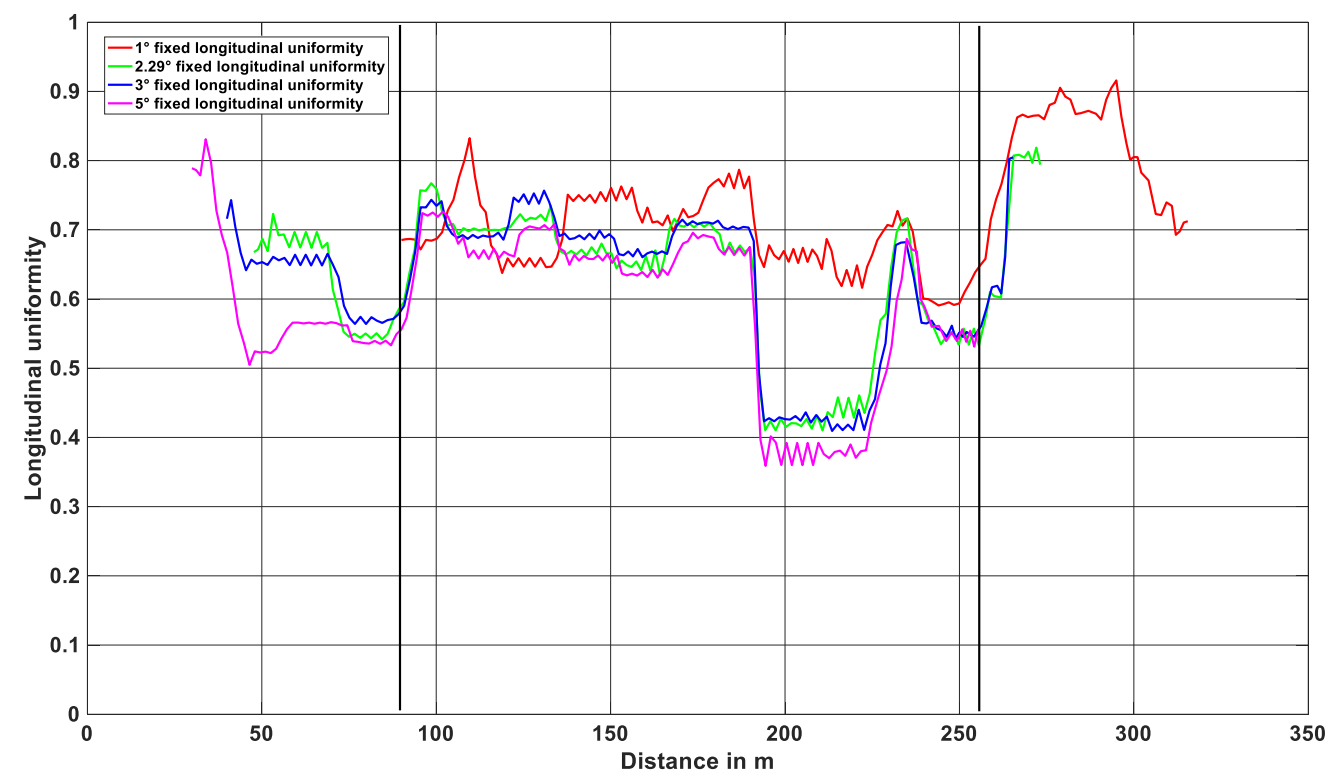

Figure 12 - Comparison of longitudinal uniformity for $1^{\circ}$ (in red), $2.29^{\circ}$ (in green), $3^{\circ}$ (in blue) and $5^{\circ}$ (in pink) fixed measurements

Table 3 summarizes the average luminance and uniformities values for the four angles of observation. The average values were calculated between the vertical black lines, i.e. on the section common to the four angles of observation.

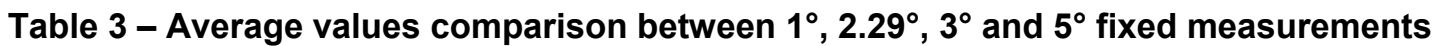

\begin{tabular}{|c|c|c|c|c|c|c|}
\hline $\begin{array}{c}\text { fixed } \\
\text { angle }\end{array}$ & $\begin{array}{c}\text { average } \\
\text { luminance }\end{array}$ & $\begin{array}{c}\text { difference } \\
\text { with } 1^{\circ}\end{array}$ & $\begin{array}{c}\text { overall } \\
\text { uniformity }\end{array}$ & $\begin{array}{c}\text { difference } \\
\text { with } 1^{\circ}\end{array}$ & $\begin{array}{c}\text { longitudinal } \\
\text { uniformity }\end{array}$ & $\begin{array}{c}\text { difference } \\
\text { with } 1^{\circ}\end{array}$ \\
\hline $1^{\circ}$ & $1.33 \mathrm{~cd} / \mathrm{m}^{2}$ & & 0.47 & & 0.69 & \\
\hline $2.29^{\circ}$ & $1.19 \mathrm{~cd} / \mathrm{m}^{2}$ & $-11 \%$ & 0.43 & $-9 \%$ & 0.62 & $-10 \%$ \\
\hline $3^{\circ}$ & $1.14 \mathrm{~cd} / \mathrm{m}^{2}$ & $-14 \%$ & 0.43 & $-9 \%$ & 0.62 & $-10 \%$ \\
\hline $5^{\circ}$ & $1.02 \mathrm{~cd} / \mathrm{m}^{2}$ & $-23 \%$ & 0.43 & $-9 \%$ & 0.59 & $-14 \%$ \\
\hline
\end{tabular}

The previous figures $(10,11$ and 12) and the average values in Table 3 show an important influence of the angle of observation on photometric measurements. Thus, average luminance, overall uniformity and longitudinal uniformity decrease as the angle of observation increases.

Since this is the first implementation of our approach, on a single set of measurements, for a single type of coating and a single lighting installation, it would be hazardous to generalize immediately our results. Nevertheless, we can mention some initial suggestions to explain our observations. Concerning the average luminance, we could mention that the increase in the angle of observation tends to reduce the effect of the specularity of pavements. For uniformities, our approach is to simulate a grid of measurements similar to that used in conventional measurements. However, as the measurement distance decreases, the more pixels in the measurement area increase. Our approach is therefore more sensitive to local differences in luminance.

\section{Conclusion and future works}

This exploratory study is based on real luminance measurements and a new method of measurement and calculation from images captured by an ILMD. The first calculations show an influence of the angle of observation on the lighting criteria. To confirm this results, we will apply our methodology to other types of pavements and different lighting installations. We will 
also conduct a cross-referenced analyse with measurements of pavement photometric characteristics on the same sites and at the same angles of observation.

\section{Fundings}

Part of this work received funding from the EMPIR programme project "16NRM02 Surface Pavement surface characterisation for smart and efficient road lighting". EMPIR programme is co-financed by the Participating States and from the European Union's Horizon 2020 research and innovation program.

\section{References}

GREFFIER, F., CHARBONNIER, P., TAREL, J.P., BOUCHER, V. and FOURNELA, F. 2015. An automatic system for measuring road and tunnel lighting performance. CIE 2015 International Conference of the 28th session of the CIE, Jun 2015, MANCHESTER, UK. pp 1647-1656.

BOUCHER, V., GREFFIER, F., FOURNELA F., DRONNEAU, R. and DUMONT, E. 2017. High Dynamic Range Imaging Luminance Measuring Device (HDR-ILMD) and applications in motion. In: CIE 2017 Midterm Meetings and Conference on Smarter Lighting for Better Life.

CEN 2015a. FD CEN/TR 13201-1:2015. Road lighting - Part 1: Guidelines on selection of lighting classes.

CEN 2015b. EN 13201-2:2015. Road lighting - Part 2: Performance requirements.

CEN 2015c. EN 13201-3:2015. Road lighting - Part 3: Calculation of performance.

CEN 2015d. EN 13201-4:2015. Road lighting - Part 4: Methods of measuring light performance.

CEN 2015e. EN 13201-5:2015. Road lighting - Part 5: Energy performance indicators.

CEN 2018. EN 1436:2018. Road marking materials - Road marking performance for road users.

CHAIN, C., MARCHAUT, V. 2008. R-tables for other observation angles: specific needs for two applications in the field of public lighting. In: CIE international symposium on road surface characteristics, Torino, Italy.

CIE 2002. CIE x023:2002. Proceedings of two CIE Workshops on Photometric Measurement Systems for Road Lighting Installations (Liège/Belgium 1994; Poitiers/France, 1996).

CIE 2010. CIE 115:2010. Lighting of roads for motor and pedestrian traffic. Vienna: CIE.

CIE 2011. CIE 194:2011. On Site Measurement of the Photometric Properties of Road and Tunnel Lighting. Vienna: CIE.

CIE 2019. CIE 140:2019. Road Lighting Calculations, 2nd Edition. Vienna: CIE.

EMPIR 2017. 16NRM02 Surface Pavement surface characterisation for smart and efficient road lighting. European EMPIR project 2017-2020. http://surface-nrm02.eu/.

IACOMUSSI, P., ROSSI, G., BLATTNER, P., et al. 2017. Metrology of road surface for smart lighting. In: LUX EUROPE, Ljubljana 2017, 103 - 107.

MUZET, V., GREFFIER, F., NICOLAÏ, A., TARON, A., VERNY, P. 2018. Evaluation of the performance of an optimized road surface/lighting combination. Lighting Research and Technology. DOI: 10.1177/1477153518808334.

SÖRENSEN, K. 1975. Report 10. In Road Surface Reflection Data. The Danish Illuminating Engineering Laboratory, Lyngby, Denmark.

STOCKMAR, A. 2015. Extension of the luminance concept in road and tunnel lighting, CIE 2015 - International Conference of the 28th session of the CIE, Jun 2015, MANCHESTER, UK. 